\title{
Aa. Vv., «Nouvelles Études Francophones» («NEF»), n. 1
}

Simona Rossi

\section{(2) OpenEdition}

\section{Journals}

\section{Edizione digitale}

URL: http://journals.openedition.org/studifrancesi/9349

DOI: 10.4000/studifrancesi.9349

ISSN: 2421-5856

\section{Editore}

Rosenberg \& Sellier

\section{Edizione cartacea}

Data di pubblicazione: 1 juin 2008

Paginazione: 228

ISSN: 0039-2944

\section{Notizia bibliografica digitale}

Simona Rossi, «Aa. VV., «Nouvelles Études Francophones» («NEF»), n. 1», Studi Francesi [Online], 154

(LII | I) | 2008, online dal 30 novembre 2015, consultato il 12 janvier 2021. URL: http://

journals.openedition.org/studifrancesi/9349; DOI: https://doi.org/10.4000/studifrancesi.9349

Questo documento è stato generato automaticamente il 12 janvier 2021.

\section{(c) (i) (9)}

Studi Francesi è distribuita con Licenza Creative Commons Attribuzione - Non commerciale - Non opere derivate 4.0 Internazionale. 


\title{
Aa. Vv., «Nouvelles Études Francophones» («NEF»), n. 1
}

\author{
Simona Rossi
}

\section{NOTIZIA}

«Nouvelles Études Francophones»(«NEF»), n. 1, printemps 2007, pp. 333.

1 Il numero della rivista qui presentato è particolarmente degno di rilievo, perché 'festeggia' i vent'anni di attività del Conseil International d'Études Francophones (Ciéf), di cui è l'organo ufficiale. Fondato da Maurice Cagnon nel 1987, il Ciéf ha fortemente voluto la nascita della rivista, che può dunque contare sull'appoggio e la competenza di una forte struttura culturale che conta iscritti in tutti i paesi. Dal cambio di nome nel 2004 (da «Études Francophones» a «Nouvelles Études Francophones», un titolo, quest'ultimo, che vuole sancire la continuità e il rinnovamento al tempo stesso) alla creazione di dettagliati dossiers di approfondimento nel 2005, «Nouvelles Études Francophones» mostra uno straordinario dinamismo e una grande capacità di porsi all'ascolto dei rapidi mutamenti culturali del nostro tempo. Costituisce un'ottima rivista specialistica, che offre al suo pubblico anche la possibilità di una rapida consultazione, grazie ai riassunti degli articoli e alle notizie bio-bibliografiche - concise ma esaurienti - sugli autori.

2 Punteggiato da innumerevoli 'angoli-memoria' in forma di piccoli saggi e brevi riflessioni redatti dai membri del Comitato a cui ha dato vita Maurice Cagnon, questo numero permette di fare un sommario bilancio della storia della rivista nel tempo. Naturalmente ciò non significa che la redazione abbia trascurato un contenuto specifico: il tema del volume è infatti il concetto di «littérature-monde en français» (p. 10), un tema di grande attualità, come dimostrano il manifesto dei quarantaquattro su "Le Monde" del 15 marzo 2007 e il volume Pour une littérature-monde, (a cura di Michel LE BRIS et Jean ROUAUD) uscito presso Gallimard nel corso dello stesso anno (cfr., in questa rassegna, la recensione di Alessandro Corio). 
3 Gli argomenti che s'incontrano sono i più vari e sono trattati da importanti critici e scrittori, quali Charles BONN, che descrive la tragica assenza della figura paterna nel romanzo magrebino; Maryse cONDÉ, che dipinge il ritratto di «une écrivaine antillaise» (p.47) e Tzvetan ToDorov, che si dedica alle innumerevoli sfaccettature del tema dell'amore in relazione all'egotismo nell'opera di Stendhal. Tra i saggi 'minori' - troppo numerosi per essere citati tutti, ma ugualmente stimolanti e meritevoli di attenzione menzioniamo quello di Bernadette CAILLER, che costruisce un originale confronto tra la poetica di Aimé Césaire e quella di Lorand Gaspar; di Fernando LAMBERT, che propone una pista d'interpretazione inedita della figura della donna nella poesia di Léopold Sédar Senghor; di Aouicha HILLIARD, infine, che riflette sul tema del percorso iniziatico nell'opera di Mohammed Dib. Una serie di articoli pluri-tematici e due ampie rassegne, una di attualità letteraria e cinematografica - che considera i luoghi più disparati del globo, dai Caraibi al Vietnam, dalla Svizzera al Québec - e una di recensioni critiche su testi di ogni tipo, letterari, politici, storici, teatrali, completano il numero. 